\title{
Correcting posterior crossbites complicated by class III malocclusions (A new technique)
}

\author{
Suhail A. Khouri* \\ Orthodontist, Ballwin, Missouri, USA
}

\begin{abstract}
TThe objective of this study is to introduce a simplified alternative approach to the current modality used in posterior crossbites correction. It is believed that the interlocking relation of posterior teeth cusps, prevents transverse forces of the palatal expanders from eliciting the desired movement, rendering the crossbite correction an oranous task for orthodontists. Thus eliminating this cuspal blockage constitutes a key step to developing a simpler approach for correction. This diagnostic concept has lead the way to formulating an alternative, and clinically convenient treatment technique that not only corrects posterior crossbites, but also effectively corrects the often coexisting class III malocclusion simultaneously. Building composite bite raisers on mandibular posterior teeth, along with the intrusive effects of the V-Bends on super elastic wires, disengage the blocked cusps of posterior teeth, stop the patient's mandibular shifted occlusion making any transverse corrective forces more effective in moving the malposed teeth segments.

This methodical and clinically applicable technique utilizes a solid force system that delivers expanding / constricting mechanics acting on buccal, rather than the palatal sides of posterior teeth, launched by placing lasting intraoral V-Bends on super elastic archwires, using the Bendistal Pliers*. Whereas these V-Bends create light and consistent, apically directed forces on both, mandibular and maxillary anterior teeth to intrude and disengage them for the class III correction, an equal and opposite side effect forces intrudes and disengages posterior teeth cusps helping the correction of posterior crossbites in the same time. This article describes in detail, the biomechanical effects and feasibility of this technique, and presents data of patients that were successfully treated during their routine adjustment visits.
\end{abstract}

\section{Introduction}

Removable acrylic expanders and Frankel appliances have long been used to correct posterior crossbites [1-3], and activated inner bows of a headgear could widen maxillary molars, all with complete patient cooperation $[4,5]$. To ensure efficiency without patient co-operation, many expanders cemented to posterior teeth [6-10], like Quad helix, Hyrax appliance, and others [11-15], were developed and dominated the correction of posterior crossbites, by opening midpalatal sutures. Also, some authors recommended surgical opening of the palatal suture in adult patients before expansion [16-18].

Searching for simpler designs, authors developed palatal arches $[19,20]$ that moved molars in more than one plane, but the high skill required to custom-make, activate and place them in the patient's palate have limited their applicability. More recently super elastic wires started to replace stainless steel in making fixed expanders [21-24], in order to deliver lighter and more consistent forces. Despite the success attainable using all these laboratory-made expanders, their long and costly fabrication procedures, and patients' inconvenience, prompts continuing search for simpler treatment approaches.

With the exception of headgear, all of the previously mentioned expander's designs deliver expanding forces from the lingual surfaces of the posterior teeth to execute the correction.

\section{Rationale of this approach}

The height $\mathrm{D}$ shown in (Figure 1A) blocking lateral excursion of the maxillary and mandibular molar cusps, may not seem deep, but the shifted path of occlusion makes it quite difficult for transverse force to effect successful crossbite correction. The concept of this approach aims primarily at eliminating this cause of difficulty by intruding and disengaging the blocked-out posterior and anterior teeth, rendering the correction of both posterior crossbites and class III malocclusion readily possible, by applying transverse forces on buccal, rather than, lingual sides of posterior teeth from activated $\mathrm{NiTi}$ archwires (Figures $1 \mathrm{~A}$ and $1 \mathrm{~B})$.

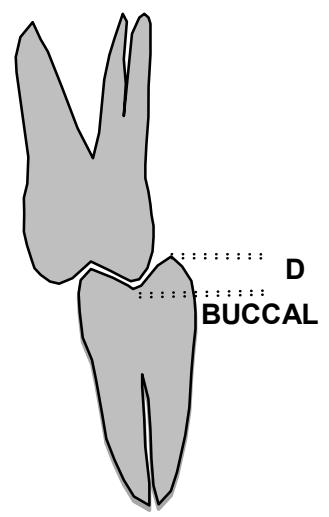

Figure 1A. Buccal cusps of the maxillary molar blocked out by the mandibular molar cusps height $\mathrm{D}$ hindering lateral excursion.

Correspondence to: Suhail A. Khouri, DDS, Orthodontics, 524 Dietrich RD, Ballwin, Missouri, Saint Louis 63024, USA, E-mail: suhailkhouri@sbcglobal.net

Key words: cross bites, posterior teeth, bendistal pliers, disengage mandibular, maxillary anterior teeth

Received: September 24, 2016; Accepted: October 18, 2016; Published: October 21,2016 


\section{The technique}

Composite build-ups were used previously on anterior teeth to raise the bite and correct crossbite [25-27], but in this technique they are placed in the central grooves of the mandibular posterior teeth Figure $1 \mathrm{~B}$, to directly disengage posterior teeth and temporarily break the habit of shifted chewing path. This initial step allows more effective transverse forces from the archwires to elicit the crossbite corrective movements.

During or after the initial teeth alignment stage, Bendistal Pliers are used to place intraoral intrusive V-Bends distal to canines on the 0.016 " NiTi maxillary archwire (with the $\mathrm{V}$ apex directed always occlusally); to intrude anterior and posterior teeth, and extrude canines and first premolars, that also help more teeth disengagement (Figure 2). Placing similar, but inverted V-bends on mandibular archwire makes opposite effects on mandibular teeth, doubling the extent and speed of the teeth disengagement, and greatly contributes to easier correction of crossbite and class III malocclusion simultaneously.

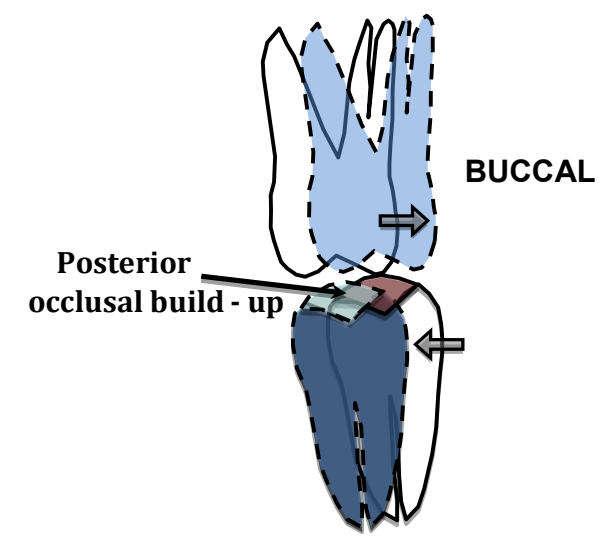

Figure 1B. shows the composite build-up in the central groove of the mandibular molar, which unlocks maxillary, molar.
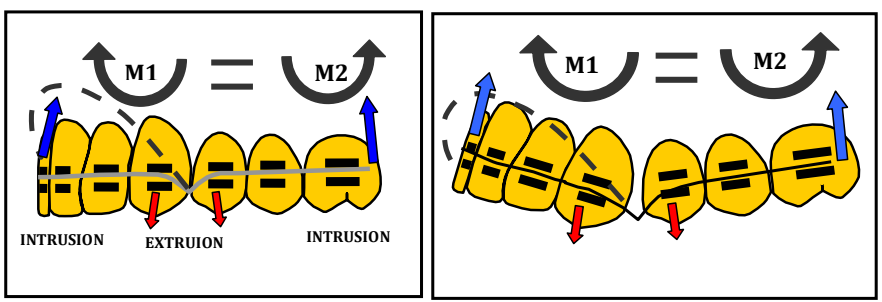

Figure 2. Shows the mechanics of V-Bends. The equal and opposite forces and moments created by V-bends favorably intrude and disengage anterior and posterior teeth distal to the bends, and extrude canines and premolar teeth adjacent to the bends, as side effect. Both the effects and side effects work favorably towards further teeth disengagement and, both crossbite and class III corrections.

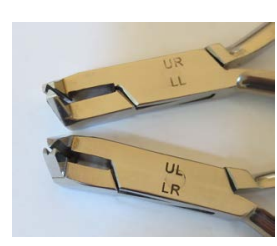

A

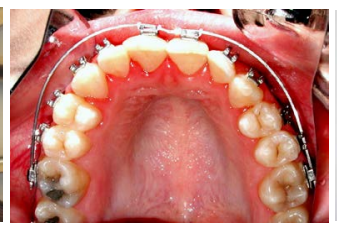

B

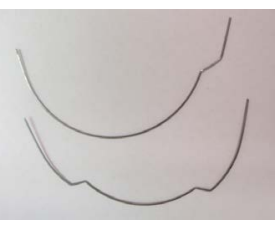

C
Figure 3A. The Bendistal Pliers set (DynaFlex) used. 3B: Shows expanding V-bend at the midline of maxillary 0.016 "X0.022" NiTi archwire before full engagement. 3C: Shows step out bends that can be used for unilateral and bilateral crossbite correction.
The efficiency of this approach is attributed primarily, to putting the following elements to clinical use:

1. The special plier's ability to place lasting activating V-bends on NiTi archwires.

2. The full engagement of active NiTi wires to brackets without losing deactivation.

3. The NiTi wire's light and consistent force delivery over long range of deactivation.

Rectangular 0.016”X0.022" NiTi archwires, or larger, with $\mathrm{V}$-Bends, may be used later on if further disengagement is required. Consequently, the posterior teeth become ready receive and respond to more effective transverse forces from archwires on their buccal sides to correct posterior crossbites, and help mandibular incisors retraction correcting anterior crossbite and class III malocclusion as well.

A Transverse V-bend placed at the midline of the maxillary NiTi archwire activates it to expand maxillary posterior teeth (Figure 3B). Also half squeezed constricting bends with the Bendistal Pliers distal to the canines on mandibular archwire, and/or additional step-out/ in bends may be used to activate both archwires and aid the crossbite corrections. These mechanics continue for about 2-4 months, to complete the corrections, after which the composite build-ups are removed. Dealing with skeletal crossbite cases, straight rectangular 0.012 "X0.022" stainless steel archwires or larger, may be needed later on to further finalize the correction.

\section{Torqueing effects}

Torqueing activations of maxillary and mandibular stainless steel rectangular archwires as illustrated in Figure 4, will help finish

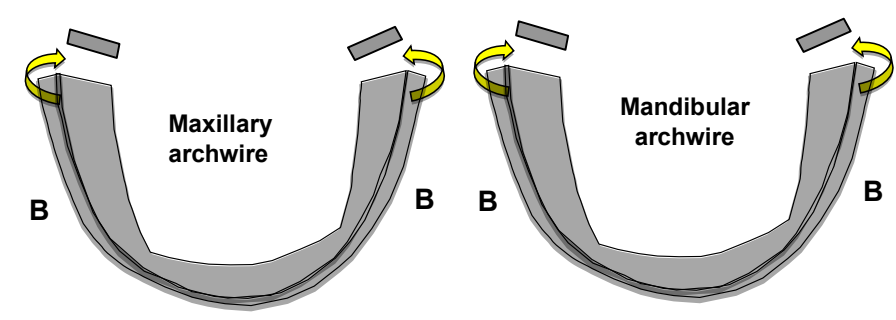

Figure 4. Torqueing activations of both maxillary and mandibular archwires, to help correct posterior bilateral crossbites. Note the clockwise torqueing activation on the right side of both the maxillary and mandibular archwires, and the anti-clockwise torqueing activation on the left sides of the same archwires. Combining these torque activations on both sides of both archwires will expand the maxillary arch, and constrict the mandibular arch serving the final correction of posterior crossbites.
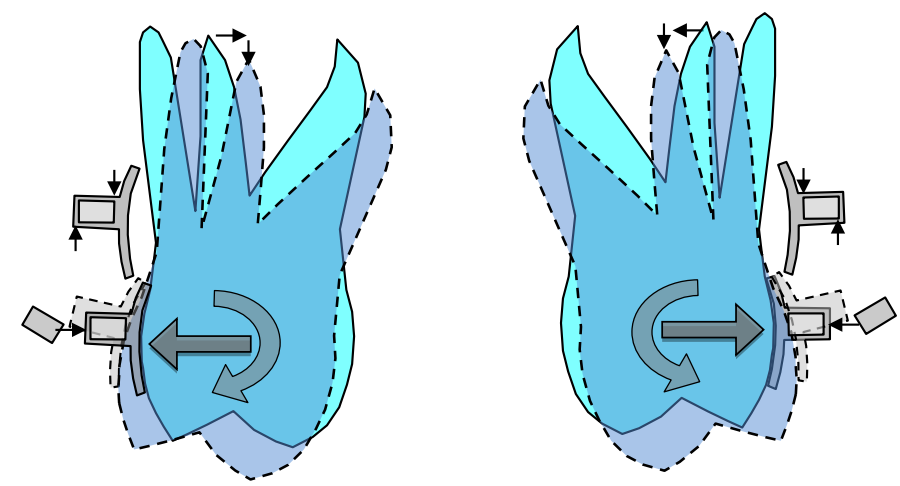

Figure 5A. Shows the effects of both the equal and opposite moments acting inside molar tubes, moving both maxillary molars buccally and their roots lingually which that help finalizing the crossbite correction. 


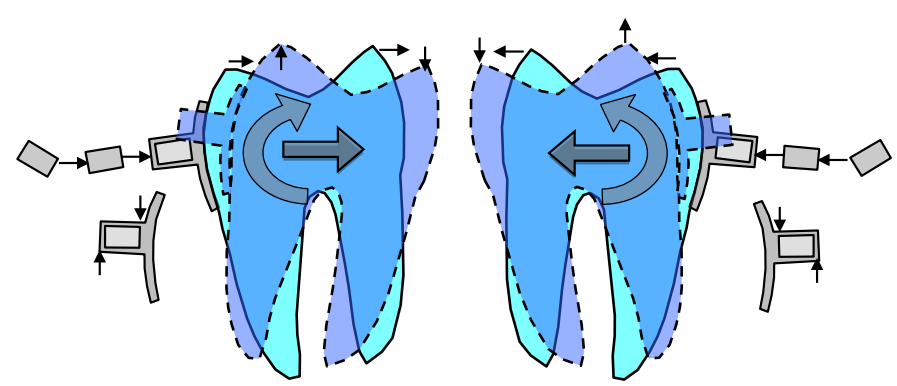

Figure 5B. Effects of the same torqueing directions on mandibular archwire. Note the equal and opposite moments moving posterior teeth crowns lingually and their roots buccally which finalizes the crossbite correction.

the correction of skeletal bilateral crossbites. Upon inserting the active archwires in molar tubes, moments at the molar tube sites for expanding maxillary posterior teeth and constricting mandibular posterior teeth crowns, will be created, while correcting the abnormal bucco-lingual axial inclination of all the affected teeth simultaneously, as illustrated in Figure 5.

Monitoring these mechanics is required at regular visits, to avoid undesirable side effects. Overtreatment of $2 \mathrm{~mm}$ per side helps minimize relapse. Finishing treatment will require the use of bite closing or/and intermaxillary elastics to achieve normal occlusal intercuspidation as usual.

\section{Discussion}

This article demonstrated the possibility of bending and activating super elastic archwires, and putting that to clinical use for executing greater tasks than teeth alignment.

This technique includes, and offers the means for, correcting class III malocclusions [28], simultaneously with correcting bilateral crossbites. The basic rationale behind this approach is the disengagement of anterior and posterior teeth as an initial mustdo step to free the blocked teeth. Achieving this clinical goal is by building composite bite raiser on mandibular posterior teeth, and intrusion of both anterior and posterior teeth achieved by placing the V-bends on NiTi archwires [28] in both arches. Using NiTi wires in this technique is not only because their easy full engagement to brackets without losing elasticity, but also because of their light, effective, and continuous forces, that are friendly to periodontal tissues.

This objective would have not been possible without the ability of bendistal pliers to place the lasting intrusive V-bending activation on super elastic archwires. It is worth mentioning, that beside the intrusion effect on anterior teeth that helps class III correction, the intrusive side effect of these V-Bends on posterior teeth was favorably used to disengage them and, and helps correct posterior cross bite.

Additionally, this technique offers one simple method of torqueing rectangular stainless steel arcwires to finalize correcting the bucco-lingual crown relations, as well as correcting the abnormal bucco-lingual axial inclinations of roots of teeth involved in skeletal crossbites as well.

This technique offers a clinically applicable alternative for orthodontic correction of not only the posterior crossbites, but also a complicating class III malocclusion simultaneously, with simple routine archwires activations from the buccal, rather than palatal, sides of teeth during regular patient's visits.

\section{References}

1. McDougall PD, McNamara JA Jr, Dierkes JM (1982) Arch width development in Class II patients treated with the Fränkel appliance. Am J Orthod 82: 10-22. [Crossref]

2. Brin I, Ben-Bassat Y, Blustein Y, Ehrlich J, Hochman N, et al. (1996) Skeletal and functional effects of treatment for unilateral posterior crossbite. Am J Orthod Dentofacial Orthop 109: 173-179. [Crossref]

3. Fíratli S, Ulgen M (1996) The effects of the FR-3 appliance on the transversa dimension. Am J Orthod Dentofacial Orthop 110: 55-60. [Crossref]

4. Kirjavainen M, Kirjavainen T, Haavikko K (1997) Changes in dental arch dimensions by use of an orthopedic cervical headgear in Class II correction. Am J Orthod Dentofacial Orthop 111: 59-66. [Crossref]

5. Kirjavainen M, Kirjavainen T (2003) Maxillary expansion in Class II correction with orthopedic cervical headgear. A posteroanterior cephalometric study. Angle Orthod 73: 281-285. [Crossref]

6. Erdinç AE, Ugur T, Erbay E (1999) A comparison of different treatment techniques for posterior crossbite in the mixed dentition. Am J Orthod Dentofacial Orthop 116 287-300. [Crossref]

7. Boysen B, La Cour K, Athanasiou AE, Gjessing PE (1992) Three-dimensional evaluation of dentoskeletal changes after posterior cross-bite correction by quad-helix or removable appliances. Br J Orthod 19: 97-107. [Crossref]

8. Wedrychowska-Szulc B (1995) Treatment of lateral cross-bite with active plates in conditions of raised dental occlusion and by the quad-helix method. Ann Acad Med Stetin 41: 233-243. [Crossref]

9. Bench RW (1998) The quad helix appliance. Semin Orthod 4: 231-237. [Crossref]

10. Erverdi N, Okar I, Kücükkeles N, Arbak S (1994) A comparison of two different rapid palatal expansion techniques from the point of root resorption. Am J Orthod Dentofacial Orthop 106: 47-51. [Crossref]

11. Braun S, Bottrel JA, Lee KG, Lunazzi JJ, Legan HL (2000) The biomechanics of rapid maxillary sutural expansion. Am J Orthod Dentofacial Orthop 118: 257-261. [Crossref]

12. Memikoglu TU, IÅŸeri H (1999) Effects of a bonded rapid maxillary expansion appliance during orthodontic treatment. Angle Orthod 69: 251-256. [Crossref]

13. Toroglu MS, Uzel E, Kayalioglu M, Uzel I (2002) Asymmetric maxillary expansion (AMEX) appliance for treatment of true unilateral posterior crossbite. Am J Orthod Dentofacial Orthop 122: 164-173. [Crossref]

14. Chang JY, McNamara JA Jr, Herberger TA (1997) A longitudinal study of skeletal side effects induced by rapid maxillary expansion. Am J Orthod Dentofacial Orthop 112 330-337. [Crossref]

15. Bell RA, LeCompte EJ (1981) The effects of maxillary expansion using a quad-helix appliance during the deciduous and mixed dentitions. Am J Orthod 79: 152-161. [Crossref]

16. Bell WH, Jacobs JD (1979) Surgical-orthodontic correction of horizontal maxillary deficiency. J Oral Surg 37: 897-902. [Crossref]

17. Lehman JA Jr, Haas AJ (1990) Surgical-orthodontic correction of transverse maxillary deficiency. Dent Clin North Am 34: 385-395. [Crossref]

18. Chung CH, Goldman AM (2003) Dental tipping and rotation immediately after surgically assisted rapid palatal expansion. Eur J Orthod 25: 353-358. [Crossref]

19. Wichelhaus A, Sander C, Sander FG (2004) Development and biomechanical investigation of a new compound palatal arch. J Orofac Orthop 65: 104-122. [Crossref]

20. Baldini G, Luder HU (1982) Influence of arch shape on the transverse effects of transpalatal arches of the Goshgarian type during application of buccal root torque. $\mathrm{Am}$ J Orthod 81: 202-208. [Crossref]

21. Ciambotti C, Ngan P, Durkee M, Kohli K, Kim H (2001) A comparison of denta and dentoalveolar changes between rapid palatal expansion and nickel-titanium palatal expansion appliances. Am J Orthod Dentofacial Orthop 119: 11-20. [Crossref]

22. Karaman AI (2002) The effects of nitanium maxillary expander appliances on dentofacial structures. Angle Orthod 72: 344-354. [Crossref]

23. Ferrario VF, Garattini G, Colombo A, Fillippi V, Pozzoli S, et al. (2003) Quantitative effects of nickel-titanium palatal expander on skeletal and dental structures in primary and mixed dentition: A preliminary study. Am J Orthod Dentofacial Orthop 73: 281285 . 
24. Kenworthy CR, Sheats RD (2001) A bonded functional ramp to aid in asymmetric expansion of unilateral posterior crossbites. Am J Orthod Dentofacial Orthop 119: 320322. [Crossref]

25. Tzatzakis V, Gidarakou I (2007) Correction of anterior crossbite using occlusal buildups. J Clin Orthod 4: 393-397. [Crossref]

26. Tzatzakis V, Gidarakou IK (2008) A new clinical approach for the treatment of anterior crossbites. World J Orthod 9: 355-365. [Crossref]

27. Janakiraman $\mathrm{K}$, Abadi S, Nanda R, Uribe F (2015) An alternative method for correcting unilateral posterior crossbite with functional shift in an adult patient. $J$ Clin Orthod 49: 525-532.

28. Khouri SA (2016) Using V-Bends on NiTi Wires for non-surgical correction of class III malocclusions. orthodontic practice.US 7: 24-29.

Copyright: $(2016$ Khouri SA. This is an open-access article distributed under the terms of the Creative Commons Attribution License, which permits unrestricted use, distribution, and reproduction in any medium, provided the original author and source are credited. 